\title{
Augmentation Strategy With Low Dose Aripiprazole in Long Standing Persistent Depressive Disorder: A Case Report from India
}

Sushil Kumar Sompur v

Assistant Professor, Department of Psychiatry, S S Institute of Medical Sciences and Research Center, PO Box 1, Davangere 577005 Karnataka, India

*Corresponding author: Sushil Kumar Sompur, Department of Psychiatry, S S Institute of Medical Sciences and Research Center, PO Box 1 , Davangere 577005 Karnataka India, Tel: 91 8884976550; E-mail: sushil.sompur@gmail.com

Received Date: July 23, 2014, Accepted Date: September 23, 2014, Published Date: September 30, 2014

Copyright: () 2014, Sushil KSV, This is an open-access article distributed under the terms of the Creative Commons Attribution License, which permits unrestricted use, distribution, and reproduction in any medium, provided the original author and source are credited.

\begin{abstract}
Depression is the leading cause of disability among women in the world, frequently under recognized and inadequately treated. In spite of the different antidepressants available at the present time, they are far from ideal and show a similar slow \& frequently incomplete response. This case report describes a $75 \mathrm{yr}$. old woman with persistent depressive disorder with intermittent major depressive episodes lasting for almost 40 years who was inadequately treated. It highlights the effectiveness of augmentation of low dose Aripiprazole in long standing persistent depressive disorder with intermittent major depressive episodes. After optimization of treatment with a known anti-depressant the augmentation strategy can produce a therapeutic response as early as 2 weeks with more than $50 \%$ reduction in symptoms on PHQ-9 scores.
\end{abstract}

Keywords: Persistent depressive disorder; Recurrence; Augmentation strategy; Aripiprazole

\section{Background}

Depression is the leading cause of disability among women in the world with a female to male risk ratio of approximately 2:1 [1,2]. But although depression affects a significant proportion of the population [1], it is under recognized and if diagnosed frequently inadequately treated. In spite of the different antidepressants available at the present time, they are far from ideal and show a similar slow \& frequently incomplete response [3,4]. Thus the need for new compounds \& augmentation strategies is as urgent and compelling as ever [1].

\section{Case Presentation}

This is a case of a 75-year old lady who was diagnosed with persistent depressive disorder with intermittent depressive episodes for nearly 40 years. She was widowed, living by herself having 4 children who were in close contact with her. Her daughter, living close by visited on a regular basis taking care of her medical and at times, domestic needs as well. The case report is based on the verbal communication or clinical interview of the patient as well as corroborative clinical evidence from available medical records. The patient had her first major depressive episode in 1974 after the birth of her first baby. She had been somewhat opposed to the arranged marriage and developed some depressive symptoms even before her marriage. She described very vividly what happened during the course of her pregnancy and thereafter when she gave birth to her baby. She reported domestic abuse after marriage, continuing through her pregnancy and thereafter. At first she developed low backache and excessive fatigue with sadness of mood present on most days. Slowly the depression worsened to the point where she started to neglect caring for the baby after childbirth and also started having poor sleep and appetite. She felt she was not being a good mother to her baby and eventually began having suicidal ideations. This was when she was taken to a doctor for the first time and was prescribed a tricyclic antidepressant and she continued to be on the same for about a year. She reported around 20\% improvement with the medication but discontinued the medications as she planned to conceive. Within a month she began to have severe symptoms of depression again. She also described continued stressors and domestic abuse on the part of her husband and his family all through this time lasting for nearly twenty years till the death of her husband. During this second episode of depression, which continued during her second pregnancy, she started to have bouts of suicidal ideations and even had a deliberate self-harm attempt by overdosing on her medications. This resulted in a spontaneous abortion. She reportedly was started on the same treatment again, however, this time around she was given Electro Convulsive Therapy (ECT) treatment as it was; at the time; one of the best treatments available according to her doctor. Although she reported around $40 \%$ improvement in symptoms with the new treatment modality, she continued to have intermittent episodes with severe depressive symptoms. Among these she described depressive episodes during postpartum periods for her next 3 pregnancies as well.

She subsequently had more episodes, relapsing every two to four years with a new episode of depression never returning to $100 \%$ baseline functioning in between the episodes. However she never reported suicidal ideations during any of these recurrent episodes except during her second pregnancy. She was given a trial of many antidepressants individually, including monoamine inhibitors, tetracyclic antidepressants, selective serotonin reuptake inhibitors, serotonin nor-epinephrine reuptake inhibitors, nor-epinephrine dopamine reuptake inhibitors, serotonin antagonist and reuptake inhibitors but never up to the maximum therapeutic dose. However, she was never initiated on any kind of medication that was used as an augmentative therapeutic modality. She did report consulting a local 
Ayurveda doctor who had given her medications in their armory but did not see any consistent effect in terms of complete recovery. The patient was also given a trial of two more courses of ECT during 2 of these episodes.

\section{Diagnosis and treatment}

When she presented to us finally she was in her fifteenth episode as she recalled it. She met the DSM V diagnostic criteria for Persistent Depressive disorder with intermittent major depressive episodes, with current episode. She had a PHQ 9 (Patient Health Questionnaire 9) [5] of 12, despite being on antidepressants at the time she consulted us. She was on already Sertraline $150 \mathrm{mg}$ at night along with a multivitamin supplement on presentation to us. She was also recently diagnosed with hypertension and was started on Atenolol $20 \mathrm{mg}$ daily. We increased her Sertraline to $200 \mathrm{mg}$ and since she was tolerating the medication well we started her on Aripiprazole $2.5 \mathrm{mg}$ daily at night as an augmentative strategy.

\section{Outcome and follow up}

The response to treatment, with a higher dose of antidepressant along with a small dose of antipsychotic as an augmentative strategy, was dramatic and her PHQ-9 score at the next visit, two weeks later was 2.

\section{Discussion}

Thus it can be argued that augmentative strategies in persistent depressive disorder even in geriatric age groups are worth a trial after optimization of treatment with a known anti- depressant. This is especially important knowing the fact that for each depressive symptom the annual decline on global cognitive measures decreases by an average of $24 \%$ in the elderly [6]. The patient in this case report presented with the same symptoms as during her previous visits with a psychiatrist and this was not unusual for her. Not being suicidal was also a good reason for using an augmentative strategy to be on the safer side. A review of literature show that augmentation with a small dose of an antipsychotic for treatment resistant Major Depressive Disorder works and works well enough to the point where the patient has complete remission from symptoms [1]. Furthermore, when considering antipsychotics, the question of the least harm is answered in the usage of Aripiprazole for the treatment and augmentation strategy, as it has been proven to have minimal side effects at low dosages [7].
In conclusion, this case illustrates the advantages of using an augmentative strategy like low-dose aripiprazole, at the same time optimizing the dose of the antidepressant as one of the augmentation strategies possible for treatment of persistent depressive disorder. In the present case, a fast and safe response in the acute phase of illness is significant [8]. What remains to be seen is whether this treatment strategy is effective in relapse prevention and more so with treatment adherence in larger population studies.

\section{Acknowledgements}

The patient has given a written informed consent to the publication of this case report. The author is grateful for her participation. I would also like to acknowledge Dr Deepti Abraham, my colleague and Assistant Professor, Department of Psychiatry, S. S Institute of Medical sciences \& RC, for her contributions in editing this paper

\section{References}

1. Chantel M (2005) Combination/augmentation strategies for improving the treatment of depression. Neuropsychiatric Disease and Treatment 1:301-309.

2. Kessler RC, Berglund P, Demler O (2003) The epidemiology of major depressive disorder: results from the National Comorbidity Survey Replication (NCS-R). JAMA, 289: 3095-105.

3. Andrade L, Caraveo-Anduaga JJ, Berglund P (2003) The epidemiologyof major depressive episodes: results from the International Consortium of Psychiatric Epidemiology (ICPE) Surveys. Int J Methods Psychiatr Res 12: $3-21$.

4. Greenberg PE, Kessler RC, Birnbaum HG (2003) The economic burden of depression in the United States: how did it change between 1990 and 2000? J Clin Psychiatry 64: 1465-75.

5. Spitzer RL, Kroenke K, Williams JB (1999) Patient Health Questionnaire Primary Care Study Group. Validation and utility of a self-report version of the PRIME-MD: the PHQ primary care study. JAMA 282: 1737-4.

6. Sanders JB, Bremmer MA, Comijs HC, Deeg DJ, Lampe IK, et al. (2011) Cognitive functioning and the natural course of depressive symptoms in late life. Am J Geriatr Psychiatry 19: 664-72.

7. Pae CU, Jeon HJ, Lee BC, Seo SJ, Kim SG, et al. (2013) Aripirazole augmentation for treatment of patients with recurrent or major depressive disorder: A 12 week prospective open-label multicentricstudy. Int Clin Psychopharmacology 28: 322-9.

8. Simmons JS, Nemeroff CB (2005) Aripiprazole augmentation of antidepressants for the treatment of partially responding and nonresponding patients with major depressive disorder. J ClinPsychiatry 66: 1216-20. 